\title{
A Global Overview on COVID-19 Pandemic: Vaccines and New Variants
}

\section{Taimoor Hassan}

School of Pharmacy and School of Medicine, Changzhou University, Changzhou, Jiangsu, China.

\begin{abstract}
Till August 25, 2021, the world registered 213 million COVID-19 cases and 4.4 million mortalities were recorded globally. Lockdowns and easing measures throughout the world have been thrown into disarray since the outbreak. Our social lives will return to normal only when a suitable vaccination will be developed and proper approved prevention methods will be practiced. To combat this epidemic, all governments and health professionals throughout the world are trying a variety of tactics and prevention approaches. In terms of providing safety to their citizens and expanding their economic operations, certain countries are regarded to be more successful than others. A plethora of vaccines had been developed; an anthology of research has been published. However, health care workers are still looking for a proper cure to overcome this pandemic, as it is spreading in different waves around the globe. This manuscript specifically highlights the contemporary review of the COVID-19 pandemic situation and mass vaccination process in view of new emerging variants.
\end{abstract}

Keywords: Coronavirus; Global Review; Pandemic; Vaccinations.

\section{Corresponding author:}

Dr. Taimoor Hassan

School of Pharmacy and School of Medicine,

Changzhou University,

Jiangsu, China.

Email: taimoorhassan408.th@gmail.com

https://doi.org/10.36283/PJMD11-1/015

How to cite: Hassan T. A Global Overview on COVID-19 Pandemic: Vaccines and New Variants. 2022;1 1 (1): 89-93. doi: 10.36283/PJMD11-1/015

\section{INTRODUCTION}

COVID-19 is a respiratory illness caused by the SARS-CoV-2 virus. Researchers around the globe are attempting to develop a vaccine. Till August 25, 2021, the world registered 213 million COVID-19 cases and 4.4 million mortalities were recorded globally (Figure 1). There are 139 total potential vaccines, currently, 42 potential vaccines are in their phase 3 clinical trials. So far, 22 vaccines have been approved in multiple countries'. The Pfizer-BioNTech COVID-19 vaccine has been authorized by the Food and Drug Administration (FDA) for people aged 16 and above. However, it will be accessible for usage under emergency use for minors aged 12-15 and will now be sold under the brand name "Comirnaty". Dr. Janet Woodcock, acting FDA Commissioner stated in the organization's news release: "While millions of individuals have already received COVID-19 vaccinations successfully, we realize that the FDA approval of a vaccine may potentially inspire further confidence for being vaccinated among masses. Today's achievement brings us one step closer to changing the trajectory of the epidemic globally" 1,2. This figure is highlighting the number of COVID-19 patients globally from January 2020 to August 2021. 


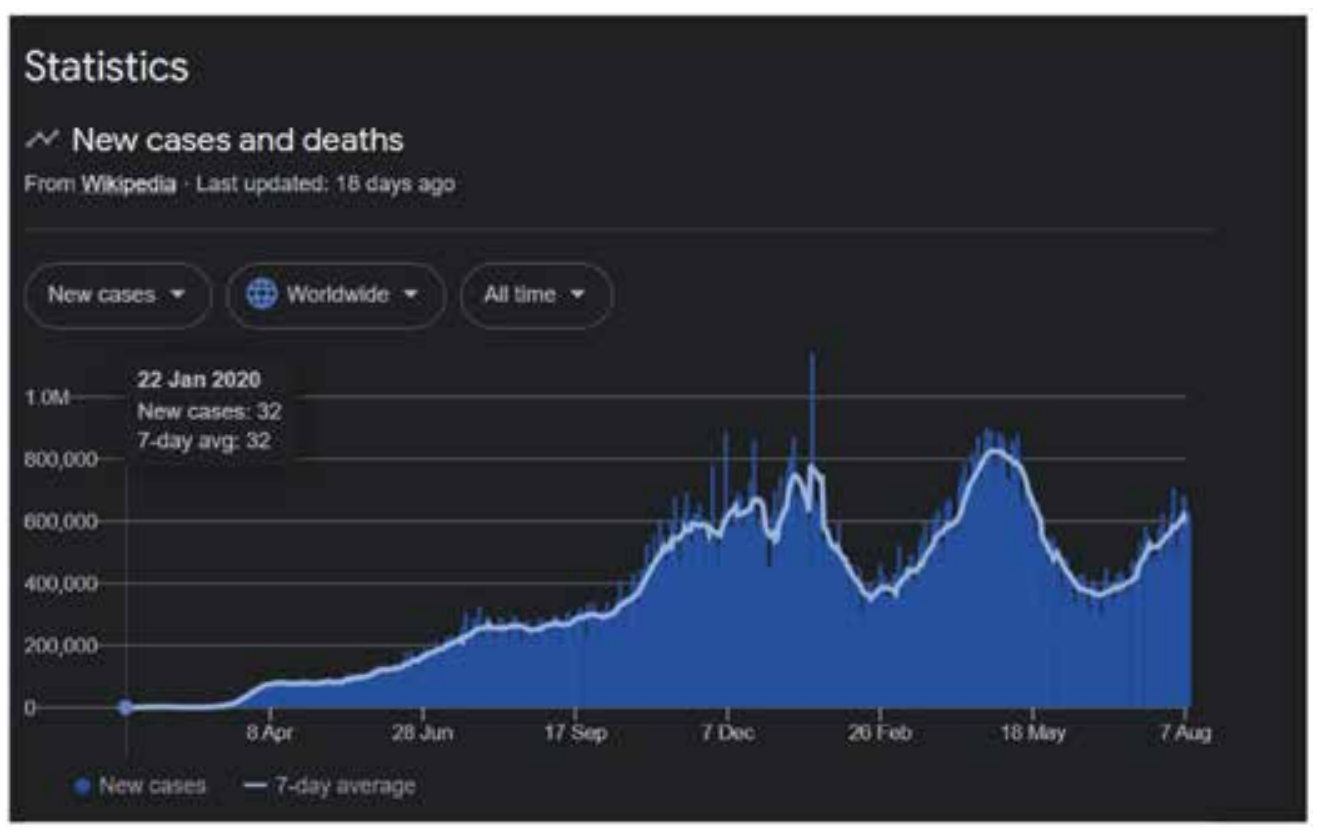

Figure 1. Statistical analysis of COVID-19 cases globally'.

\section{DISCUSSION}

The situation of COVID-19 pandemic and successes achieved in the development of COVID-19 vaccinations can be reviewed looking at an updated global perspective.

\section{Can intradermal administration will increase} COVID-19 vaccine doses?

COVID-19 vaccinations are being delivered intradermally (below the skin) in Thailand as the number of cases increases and vaccines become scarce. Intradermal injections need $25 \%$ less vaccine to generate the same degree of protection as compared to muscle injections ${ }^{3}$. Astrazeneca COVID-19 vaccines are manufactured in Thailand, and Thailand orders enough doses of other brands to immunize the country's population, but supplies are not delivered rapidly enough to Thais so that they may be able to get extra vaccines while they wait for their doses to come if intradermal delivery succeeds ${ }^{4}$.

\section{Effectiveness of vaccine boosters on delta variant}

Due to its increased transmissibility over previous strains, Delta has quickly become the prevalent strain in numerous nations, including Britain, India, and Pakistan. However, according to some reports: COVID-19 vaccines are less effective in preventing Delta strain. When asked whether the booster injections may assist in the containment of this virus? Experts responded that they believe they can ${ }^{5}$.

Moderna for minors (aged 12-17) approved in the United Kingdom (UK)

Moderna has been licensed by the UK's Medicines and Healthcare Products Regulatory Agency
(MHRA) for people aged 12-17. Dr. June Raine, the MHRA's chief executive, writes in a government news release: "It is with great pleasure, I confirm that the COVID-19 vaccine manufactured by Moderna has now been approved for use in children aged 12 to 17 years. For this age range, the vaccination is both safe and efficacious" 1,5,6.

\section{Can pregnant women get COVID-19 vaccine jabs? CDC updates}

According to the Centers for Disease Control and Prevention (CDC), COVID-19 vaccination is safe for pregnant women and negates erroneous allegations that the injections cause infertility or miscarriages. The source had been updated to include new evidence on the safety of mRNA vaccines (Pfizer-BioNTech or Moderna) that showed no increased risk of miscarriage in women who had taken at least one dose of vaccine before 20 weeks. In an interview with NBC News, CDC Director Dr. Rochelle Walensky said, "The CDC strongly urges all pregnant women or those who are considering pregnancy, as well as those who are nursing, to receive vaccines" 7 .

Nevertheless, because of the highly transmissible Delta variant as well as COVID-19's devastating effects on unvaccinated pregnant women, it has never been more important to promote immunizations. As a result of the extremely contagious Delta form of COVID-19, the United States, India, and Brazil are now dealing with an upsurge in the hospitals, and health authorities also noticed several pregnant women who have become victimized by the disease in the past few weeks. However, according to the Centers for Disease Control and 
Prevention (CDC), approximately only $23 \%$ of pregnant women have gotten even one dosage of the COVID-19 vaccines. In any way, vaccines, including the COVID-19 vaccines, do not increase the risk of infertility in men or women ${ }^{8}$.

FDA to approve vaccine boosters for immunocompromised people

According to recent resources, FDA is reportedly ready to approve the delivery of extra COVID-19 vaccine booster injections for immunocompromised patients. During the next couple of weeks, the FDA will evaluate relevant data from CDC. As part of the study, researchers will explore if an extra booster injection might assist increase protection against COVID-19 in those who are clinically immunocompromised ${ }^{?}$.

\section{Sputnik $\mathbf{V}$ to be effective $83 \%$ against delta strain of COVID-19: says Health Minister}

Despite lower levels of protection, the Sputnik $V$ COVID-19 vaccine produced by Russia appears to be extremely efficient against SARS-Delta CoV-2's strain. Russian Health Minister Mikhail Murashko stated that the Gam-COVID-Vac injection, also known as Sputnik $V$, was about $83 \%$ effective against the Delta strain, which currently accounts for more than $90 \%$ of new infections. Russian news outlet Telegraph Agency of the Soviet Union (TASS) claimed that the vaccine's effectiveness against serious illness also exceeds 95\%. Before this, the vaccine's researchers predicted that the injection would have a $90 \%$ efficiency. In phase 3 clinical trials, researchers find out that the vaccine was approximately $92 \%$ effective against the original strain of the coronavirus. Sputnik $V$ has been authorized by 67 nations, including India, Brazil, the Philippines, and Turkey. In addition, Germany also plans to purchase up to 30 million doses of the vaccine after it is approved by the European Medicines Agency (EMA) ${ }^{1,9}$.

Is the second dose of mRNA vaccine being safe after an allergic response from the first dose?

An estimated $2 \%$ of individuals experienced adverse side-effects from mRNA COVID-19 vaccinations, such as the Pfizer-BioNTech and Moderna vaccines. The great majority of these responses are mild. A new study article published in the Journal of American Medical Association examined how these people responded to their second dosage. The study included information from 159 people who experienced an adverse reaction from their first dose of mRNA vaccination and then received a second dose?.

According to the study, 47/159 individuals took an antihistamine before the second dosage. "All 159 patients, including 19 with first-dose anaphylaxis, tolerated the second dose. Thirty-two (20\%) patients had acute and possibly allergic symptoms associated with the second dosage that was self-limited, mild, and/or alleviated with antihistamines alone"2,6.

Hesitation towards COVID-19 vaccine jabs among low- and middle-income countries

According to a new study published in the journal 'Nature Medicine', populations from low- and middle-income countries (LMICs) had less COVID-19 vaccination reluctance than those from high-income nations. In addition to this, seven studies were conducted in low-income countries (Sierra Leone, Burkina Faso, Rwanda, Uganda, and Mozambique) five studies were undertaken in nations with a lower-middle-income level (India, Pakistan, Nepal, and Nigeria) and one study was done in middle-income country (Colombia). According to the data, the average vaccination acceptance rate in LMICs was $80.3 \%$. They also demonstrated that even the LMICs with the lowest rates - Burkina Faso and Pakistan - performed better in terms of COVID-19 vaccine uptake than Russia and the United States. Vaccine uptake rates were $66.5 \%$ in both Burkina Faso and Pakistan ${ }^{10}$. Ironically, the digits were $64.6 \%$ in the United States and $30.4 \%$ in Russia. Dr. Alexandra Scacco, a senior research fellow at the WZB Berlin Social Science Center and co-author of the study, observed that "Across nations, we see that adoption of COVID-19 vaccines is typically somewhat diverse, it may be due to their novelty" "1.

\section{What do we need to know about DNA vaccines?}

The field of medicine continues to see radical new techniques for combating COVID-19, with the most recent development being in vaccination ${ }^{12}$. India has approved the world's first DNA vaccine for use in an emergency against COVID-19, joining almost a dozen additional DNA vaccine candidates in clinical testing ${ }^{13}$. The ZyCoV-D vaccine works by priming the immune system against the virus that causes COVID-19, SARS-CoV-2. It is also administered without the use of an injection ${ }^{14}$. This vaccine differs from the messenger RNA (mRNA) technology utilized in two of the currently approved COVID-19 vaccines, Moderna and Pfizer-BioNTech, both of which have received praise for their inventiveness ${ }^{14}$

Table 1 highlights the concerns about the COVID-19 pandemic globally. It mentions the number of COVID-19 cases and mortalities, it further highlights the mass vaccination process which has started globally. This table also gives information about serious concerns of people regarding the administration of COVID-19 vaccinations in people who are pregnant, immunocompromised, and allergic. One of the most important social issues has also been discussed in this table about the acceptance of vaccines in certain nations. 
Table 1: A quick review of the global COVID-19 pandemic.

\begin{tabular}{|l|c|c|}
\hline CoVID-19 Concerns Globally & $\begin{array}{c}\text { Update, Statistics and } \\
\text { Outcomes }\end{array}$ & $\begin{array}{c}\text { Cited from } \\
\text { References }\end{array}$ \\
\hline No. of COVID-19 cases globally & 313 million & 1 \\
\hline No. of COVID-19 mortalities globally & 4.4 million & 1 \\
\hline No. of approved vaccines globally & 22 & 1 \\
\hline $\begin{array}{l}\text { No. of COVID-19 vaccination administration globally } \\
\text { vaccinated, 5.04 billion } \\
\text { partially vaccinated }\end{array}$ & Yes & 1 \\
\hline $\begin{array}{l}\text { Can pregnant women get COVID-19 vaccines? } \\
\text { vaccines? }\end{array}$ & Yes & 7,8 \\
\hline $\begin{array}{l}\text { Is second dose of mRNA vaccine being safer after } \\
\text { allergic response from the first dose? }\end{array}$ & Yes & 9 \\
\hline $\begin{array}{l}\text { Which countries are more reluctant towards COVID- } \\
19 \text { vaccine jabs? }\end{array}$ & High income countries & 7 \\
\hline
\end{tabular}

\section{CONCLUSION}

Coronavirus is declared a pandemic by WHO in the previous year. Since its inception health pantheons and several big Whig pharmaceutical companies striving best to contain this virus by implementing a plethora of preventive measures and developing COVID-19 vaccines. So far, many vaccines have been developed and their results are very promising. Hitherto, scientists have achieved marvelous results regarding these vaccines such as these vaccines are safe for younger people, pregnant and lactating women, immunocompromised people. Furthermore, vaccine boosters are also efficacious against the deadliest strains of COVID-19 such as Delta, Epsilon, Beta, and Alpha. Now people across the globe are trusting these vaccines and voluntarily administering them.

\section{ACKNOWLEDGMENTS}

The author would like to acknowledge Ms. Saleha from the Department of Anthropology, Quaid-E-Azam University, Islamabad, for her help in selecting this topic.

\section{CONFLICT OF INTEREST}

The author declared no conflict of interest.

\section{AUTHORS' CONTRIBUTION}

$\mathrm{TH}$ had given the concept of the study, written the manuscript, and reviewed it.

\section{REFERENCES}

1. MNT News. COVID-19 vaccines: Live updates. Medical News Today. [Internet]. Available online at: https://www.medicalnewstoday.com/articles/covid-19-vaccine-live-updates\# 1 [Cited on August 25, 2021]

2. Bloomberg News. Record Cases in New South Wales;
Japan Emergency: Virus Update. [Internet]. Available online at: https://mww.bloomberg.com/ news/articles/2021-08-24/goldman-sachs-mandates-vaccines-idaho-near-crisis-virus-update [Cited on August 25, 2021]

3. Kattering health. COVID-19 August update. Kattering Health. [Internet]. Available online at: https://ketteringhealth.org/covid-19-august-update/ [Cited on August 25, 2021]

4. Lavaidier M. Daily vaccination rate is rising among Americans getting their first shot, official say. Washington Post. [Internet]. Available online at: https://www. washingtonpost.com/nation/2021/08/24/covid-delta-variant-live-updates/ [Cited on August 25, 2021]

5. Press News release. PSD News release: department of public safety covid-19 update. Governer.Hawaii.gov. [Internet]. Available online at: https://governor.hawaii.gov/newsroom/psd-news-release-department-of-public-safety-covid-19-update-17/ [Cited on August 25, 2021]

6. UCA. COVID-19 Update: August 24, 2021. University of Central Arkansas. [Internet]. Available online at: https://uca.edu/news/covid-19-update-august-24-2021/ [Cited on August 25, 2021]

7. Marin county coronavirus update: COVID-19 Status Update for 08/24/2021. Marin Health \& Human Services. [Internet]. Available online at: https://coronavirus.marinhhs.org/covid-19-status-update-08242021 [Cited on August 25, 2021]

8. Lefebvre $C$. The Delta variant is changing the game': Updated COVID-19 modelling outlines the potential impact of the fourth wave in Manitoba. Winnipeg News. [Internet]. Available online at: https:// winnipeg.ctvnews.ca/the-delta-variant-is-changing-the-game-updated-covid-19-modelling-outlinesthe-potential-impact-of-the-fourth-wave-in-manitoba-1.5559129 [Cited on August 25, 2021]. 
9. FDA News Release. Coronavirus (COVID-19) Update: FDA Authorizes Additional Vaccine Dose for Certain Immunocompromised Individuals. US FDA. [Internet]. Available online at: https://www.fda.gov/news-events/press-announcements/coronavirus-covid-19update-fda-authorizes-additional-vaccine-dose-certain-immunocompromised [Cited on August 25, 2021] 10. Lennon A. Delta variant: How can we slow the spread? Medical News Today. [Internet]. Available online at: https://www.medicalnewstoday.com/articles/delta-variant-how-can-we-slow-the-spread [Cited on August 25, 2021]

11. Fraser N, Brierley L, Dey G, Polka JK, Pálfy M, Nanni $\mathrm{F}$, et al. Preprinting the COVID-19 pandemic. bioRxiv. 2021;20(2):05-11. doi: 10.1101/2020.05.22.111294

12. Bloomberg News. Record Cases in New South
Wales; Japan Emergency: Virus Update. [Internet]. Available online at: https://www.bloomberg.com/ news/articles/2021-08-24/goldman-sachs-mandates-vaccines-idaho-near-crisis-virus-update [Cited on August 25, 2021]

13. Skegg D, Gluckman P, Boulton G, Hackmann H, Karim SS, Piot $P$, et al. Future scenarios for the COVID-19 pandemic. Lancet. 2021;397(10276):777-778. doi: 10.1016/S0140-6736(21)00424-4

14. Press News release. PSD News release: department of public safety covid-19 update. Governer.Hawaii.gov. [Internet]. Available online at: https://governor.hawaii.gov/newsroom/psd-news-release-department-of-public-safety-covid-19-update-17/ [Cited on August 25, 2021]. 